(Aus der Abteilung für Chemotherapie des Instituts für Infektionskrankheiten ,Robert Koch".)

\title{
Uber die Konservierung von Streptokokken und die Erhaltung ihrer Tierpathogenität nach dem Ungermannschen Vorfahren.
}

\author{
Von \\ Fritz Pulvermacher.
}

Experimentelle Arbeiten mit Streptokokken, wie sie seit längerer Zeit in unserem Laboratorium ausgeführt werden ${ }^{1}$ ), veranlaßten ein eingehenderes Studium der Pathogenität zahlreicher Streptokokkenstämme mit dem Ziele, möglichst regelmäßige Infektionen verschiedener Art zu erreichen.

In der Regel wurden die Streptokokken in 1- bis höchstens 2 tägigem Turnus von Blutagarplatten mit einem Zusatz von $8 \%$ defibriniertem Ziegen- oder Pferdeblut in 10 proz. Pferdeserumbouillon und wieder auf Blutagar überimpft. Die Einschaltung der Blutagarpassage zwischen die flüssigen Nährmedien geschieht, um die Reinheit der Kultur zu kontrollieren und bei den hämolytischen Stämmen etwa abgespaltene grüne Kolonien zu erkennen.

Die Pathogenität der Streptokokken wird auf solche Weise eine gewisse Zeit hindurch nicht verändert. Man kann damit rechnen, daß die Pathogenität für Mäuse sich 4-6 Wochen hindurch unverändert erhält. Wir haben eine Anzahl Streptokokken bei dieser Art der Fortzüchtung 4-5 Monate, z. T. fast 1 Jahr hindurch zur Erzeugung der subcutanen Streptokokkenphlegmone bei der Maus benutzen können. Selbstverständlich mußte hicrbei durch fortlaufende Kontrollversuche die wirksame Dósis sorgfältig kontrolliert und dem allmählichen Sin-

1) Morgenroth und Bumke, Dtsch. med. Wochenschr. 1914, S. 538. - Morgenroth und Tugendreich, Berl. klin. Wochenschr. 1916, Nr. 29; Biochem. Zeitschr. r9, 257. 1917. - Morgenroth, Dtsch. med. Wochenschr. 1919, Nr. 19. - Morgenroth und Abraham, Dtsch. med. Wochenschr. 1920, Nr. 3. - Morgenroth, Dtsch. Zeitschr. f. Chirurg. 165, 149. 1921. - Morgenroth, Schnitzer und Rosenberg, Dtsch. med. Wochenschr. 1921, Nr. 44. - Morgenroth, Klin. Wochenschr. 1922, S. 353. Morgenroth, Biberstein und Schnitzer, Dtsch. med. Wochenschr. 1920, Nr. 13. Schnitzer und $v$. K̈̈̈hlewein, Zeitschr. f. Hyg. u. Infektionskrankh. 92, 492. 1921. Schnitzer und Munter, Zeitschr. f. Hyg. u. Infektionskrankh. 93, 96. 1921 und 94, 107. 1921. - Morgenroth und Abraham, Zeitschr. f. Hyg. u. Infektionskrankh. \$4, 163. 1921 . 
ken der Pathogenität, wie es im Laufe der Monate regelmäßig in die Erscheinung trat, durch entsprechende Erhöhung der Infektionsdosis Rechnung getragen werden. Gelegentlich kommt es nach längerer Fortzüchtung bei 1- bis 2 tägiger Überimpfung vor, daß ein Stamm seine Pathogenität völlig verliert. Auch die Weiterimpfung von Serumbouillon in Serumbouillon ohne Blutagarpassage bietet, wie wir in besonderen Versuchen festgestellt haben, keine größere Sicherheit bezüglich der Erhaltung der Virulenz. Da frische Streptokokken immer zur Verfügung stehen und sich nach unseren Erfahrungen an etwa 150 Stämmen ohne Ausnahme zur Erzeugung typischer Phlegmonen bei Mäusen eignen ${ }^{1}$ ), tut man am besten, die älteren Stämme rechtzeitig auszuschalten und durch frische zu ersetzen.

Das Verfahren der Fortzüchtung der Streptokokken auf defibriniertem Menschenvollblut nach Meyer und Ruppel wurde anfangs mit gutem Erfolge angewandt. Morgenroth, Biberstein und Schnitzer (l. c.) haben auf diese Weise die - an sich nicht hohe - Virulenz des Streptokokkus 23 längere Zeit konstant erhalten können ohne eine Abschwächung, allerdings auch ohne eine Erhöhung der tierpathogenen Eigenschaften des Stammes zu verzeichnen. Wir mußten später von dieser Methode abgehen, ohne sie an vielen Streptokokkenstämmen systematisch geprüft zu haben, da uns bei der Ausdehnung der Versuche Menschenblut nicht in den nötigen Mengen zur Verfügung stand.

Wir haben fernerhin versucht, durch häufige Mäusepassagen den Virulenzgrad frischer, vom Menschen gezüchteter Streptokokken konstant zu erhalten. Da über das Verhalten derartiger Stämme bei fortlaufenden Tierpassagen bisher nur wenig bekannt ist, eine erhebliche Virulenzsteigerung bei diesem Verfahren nicht regelmäßig zu erwarten war, konnte die Möglichkeit einer gewissen Virulenzerhaltung immerbin in Betracht gezogen werden. Die Versuche zeigten nun, daß durch Tierpassagen der ursprüngliche pathogene Charakter eines hämolytischen Streptokokkus im wesentlichen unverändert bleibt, daß vor allem eine Wiederherstellung oder Steigerung der Pathogenität bei den in Abschwächung begriffenen Stämmen nicht zu erzielen ist.

So konnten wir bei dem von Morgenroth bereits beschriebenen hämolytischen Streptokokkus 23 auch durch systematisch wiederholte Tierpassagen keine Erhöhung der ursprünglichen geringen Virulenz für weiße Mäuse erzielen, und das von Schnitzer und v. Kühlewein (l. c.) beschriebene völlige Erlöschen der Virulenz ließ sich bei diesem Stamm nicht aufhalten.

Ähnliche Beobachtungen machten wir bei dem Str.Bl., der von einer Meningitis gezüchtet war. Dies war ein für Mäuse hochvirulenter, hämolytischer Stamm, den wir fortlaufend durch regelmäBige Verimp-

1) Vgl. Fritz Pulvermacher, Inaug.-Diss. Berlin 1922. 
fung des Herzblutes von Maus zu Maus weiterführten. Von einer nach der 17. Tierpassage angelegten Serumbouillonkultur töteten bei intraperitonealer Verimpfung $0,5 \mathrm{ccm}$ einer Verdünnung von $1: 1$ Million Mäuse in 24 Stunden. Auf dieser Virulenzstufe hielt sich der Stamm bei der gewöhnlichen, oben geschilderten Überimpfung etwa 5 Wochen. Dann nahm seine Virulenz ab $-0,5 \mathrm{ccm}$ einer Verdünnung $1: 100$ töteten Mäuse nicht mehr -, und weitere Tierpassagen konnten sie nicht wieder auf die alte Höhe bringen, ja nicht einmal die fortschreitende Abschwächung aufhalten. Nach der 40. Mäusepassage war dio tödliche Dosis auf $0,5 \mathrm{ccm}$ einer $1: 10$ verdünnten Serumbouillonkultur gesunken, und selbst der Erfolg dieser hohen Dosis war nicht mehr ganz regelmäßig.

Bei hochvirulenten, für Müuse angezüchteten Laboratoriumsstämmen ist es möglich, durch Tierpassagen geringe Virulenzschwankungen auszugleichen.

Das von Ungermann ${ }^{1}$ ) für die Konservierung empfindlicher Bakterien, vor allem der Meningokokken und Gonokokken angegebene Verfahren bot uns die Möglichkeit, Streptokokken jeden Virulenzgrades beliebig lange unter Erhaltung ihrer ursprünglichen Eigenschaften aufzubewahren. Ungermann hielt Meningokokken und Gonokokken in verdünntem oder unverdünntem inaktivem Kaninchenserum unter Luftabschlu $\beta$ durch flüssiges Paraffin und konnte auf diese Weise sowohl alte Laboratoriumskulturen als auch frisch vom Menschen gewonnene Stämme monatelang, einzelne sogar länger als ein Jahr lebensfähig und virulent erhalten; dabei bewährte sich das unverdünnte Serum am besten. Seine Versuche, Pneumokokken und Streptokokken in Serum zu konservieren, zeigten, daß es gleichfalls möglich ist, diese Keime monatelang, auch bei dauernder Bebrütung, überimpfbar zu halten. Die Tierpathogenität der Pneumokokken wio der Streptokokken ging nicht verloren, wenn auch bei den letzteren eine Abschwächung der 6 Wochen alten Kultur zu verzeichnen war ${ }^{2}$ ).

Wir sind bei der Verwendung der Serummethodo nach Ungermann dazu übergegangen, statt des Kaninchenserums das uns stets zugängliche Pferdeserum zu benutzen, das gleichfalls 1 Stunde bei $60^{\circ} \mathrm{C}$ inaktiviert wird. Nach Ungermanns Vorschrift füllen wir dann jo $1 \mathrm{ccm}$ dieses Serums in enge Reagensgläser (Uhlenhuthröhrchen), überschichten mit 0,2-0,3 ccm sterilen, flüssigen Paraffins und sterilisieren die fertigen, mit Wattestopfen verschlossenen Röhrchen noch-

1) Ungermann, Arb. a. d. Reichs-Gesundheitsamt 51, 180. 1919.

2) Die Methode Neufelds (Eintrocknung der Organe infizierter Tiere im Exsiccator), die sich uns für Pneumokokken seit Jahren bowührt hat, ist von Neufeld selbst mit Erfolg auch auf Streptokokken angewandt worden. (S. Neufeld-Haendel, Handb. v. Kolle-Wassermann 4, 524.) 
mals 1 Stunde bei $60^{\circ} \mathrm{C}$ im Brutschrank nach. Am Schlusse dieses Prozesses bringen wir - was von Ungermann noch nicht angegeben ist - durch kurzen Aufenthalt der Röhrchen im Wasserbad bei $70^{\circ} \mathrm{C}$ das Serum in einen gallertigen Zustand und bewahren die Röhrchen im Eisschrank auf. Die Beimpfung erfolgt mit langen Glascapillaren, und: zwar übertragen wir immer reichliche Mengen einer dichten Verreibung von Oberflächenkultur von Blutagar oder einer Serumbouillonkultur in das Serum und bewahren nach 24 stïndigem Aufenthalt bei $37^{\circ} \mathrm{C}$ die Röhrchen bei Zimmertemperatur im Dunkeln auf. Die Streptokokken zeigen in dem gallertig gewordenen Serum ein Wachstum, das an das Verhalten in Stichkulturen erinnert; doch erscheint das Wachstum mehr bandartig; oft sicht man mehrere kulissenartig angeordnete Bänder zarter Streptokokkenkolonien. Die Entnahme aus diesen Serumröhrchen erfolgt gleichfalls mit Glascapillaren, mit denen kleine Mengen auf Blutagar und Serumbouillon übertragen werden.

- Bei der Konservierung nach Ungermann hielten sich die von uns untersuchten hämolytischen Streptokokkenstämme längere Zeit lebensfähig und - was von größter Bedeutung ist - auch in ihrer Tierpathogenität unverändert. Es hat sich als zweckmäßig erwiesen, alle 6-8 Wochen die Keime in frische Röhrchen zu übertragen. Wir schalten bei dieser Gelegenheit stets eine Blutagarpassage dazwischen. Etwaige Virulenzprüfungen werden mit einer Serumbouillonkultur vorgenommen, welche von dieser Blutagarplatte erhalten worden ist.

Wir haben nun die Beobachtung gemacht, daß einzelne Stämme ohne jede Überimpfung sich ganz besonders lange lebensfähig und virulent erhalten, und zwar konnten wir diese von Ungermann (l. c.) bereits erwähnte Tatsache an zwei für Mäuse hochpathogenen Laboratoriumsstämmen von Streptococcus haemolyticus bestätigen.

I. Streptokokkus $\mathrm{H}_{2}$. Hochvirulenter, durch Mäusepassage ${ }^{1}$ ) gegangener Laboratoriumsstamm, der uns im Juni 1920 von dem Law boratorium der Höchster Farbwerke freundlichst überlassen wurde. Dieser Streptokokkus tötete Mäuse bei intraperitonealer Infektion noch durch $0,3 \mathrm{ccm}$ einer Verdünnung von 1:10 Millionen einer 24stündigen Serumbouillonkultur binnen 48 Stunden; 1 : 100 Millionen ging nur gelegentlich bei einzelnen Tieren an. Der Stamm wurde auf Serum verimpft und aufgehoben.

- Am 8. IX. 21 wurden zwei von derartigen, 14 bzw. 12 Monate in Serumröhrchen gehaltenen Kulturen des Streptokokkus $\mathrm{H}_{2}$ auf Blutagar abgeimpft. Sie wuchsen noch reichlich und waren stark hämo-

1) Die Angabe von Schnitzer und Munter (Zeitschr. f. Hyg. u. Infektionskrankh. 94, 108), daß dieser Stamm keine Tierpassage durchgemacht habe, wird hiermit auf Grund neuerlicher Informationen durch Herrn Dr. Joseph, Leiter des bakteriologischen Laboratoriums der Höchster Farbwerke, richtig gestellt. • 
lytisch. Am 9. IX. wurden sie in Serumbouillon weiter verimpft und die Virulenz der 24stündigen Serumbouillonkultur bei intraperitonealer Infektion von Mäusen ermittelt. Das Ergebnis dieser Virulenzeinstellung zeigt Tabelle I, in der die Pathogenität des Ursprungsstammes im Juni 1920 vor seiner Konservierung zum Vergleich mit aufgeführt ist.

Tabelle I

\begin{tabular}{|c|c|c|c|c|}
\hline \multirow[t]{2}{*}{ Stamm } & \multirow{2}{*}{$\begin{array}{l}\text { Dauer der Anfbewahrung } \\
\text { im Serum }\end{array}$} & \multicolumn{3}{|c|}{$\begin{array}{l}\text { Infektion intraperit. mit je } 0,3 \mathrm{ccm} \\
\text { der Verdlinnungen }\end{array}$} \\
\hline & & $1: 100000$ & 1:1 Mill. & $1: 10$ Mill. \\
\hline 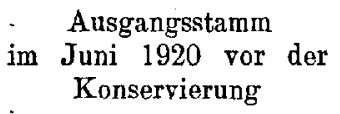 & - & $\dagger 2 . \mathrm{Tag}$ & $+2 . \mathrm{Tag}$ & † 2. Tag \\
\hline $\begin{array}{r}\text { Konservierte Stammo a) } \\
\text { b) }\end{array}$ & $\begin{array}{l}12 \text { Monate } \\
14 \text { Monate }\end{array}$ & $\begin{array}{l}\text { † 2. Tag } \\
\dagger \text { 2. Tag }\end{array}$ & $\begin{array}{l}+ \text { 2. Tag } \\
+ \text { 2. Tag }\end{array}$ & $\begin{array}{l}+ \text { 3. Tag } \\
+ \text { 3. Tag }\end{array}$ \\
\hline
\end{tabular}

Streptokokkus $\mathrm{H}_{2}$ hat also seine Virulenz über ein Jahr lang im Serumröhrchen unverändert bewahrt.

II. Streptokokkus Aronson. Versuche mit dem gleichfalls für Mäuse hochpathogenen, früher vielfach durch Mäuse gegangenen Streptokokkus Aronson zeigten, daß die in dem zuerst im Juli 1920 beimpften Serumröhrchen befindlichen Keime ebenfalls über ein Jahr lang ihre hohe Virulenz für Mäuse unverändert bewahrt hatten. Im März 1922, d. h. ungefähr $1^{3} / 4$ Jahre nach der Beimpfung, war jedoch kein Wachstum von Streptokokken aus diesem Röhrchen mehr zu erzielen. Nun war aber am 2. VII. 1921 von dem ersten Serumröhrchen auf ein anderes übertragen worden; von diesem zweiten Ungermannröhrchen impften wir am 24. IV. 1922 auf Blutagar und Serumbouillon ab. Es wuchsen auf Blutagar reichlich zarte hämolytische Kolonien, das Wachstum in Serumbouillon war trübe mit geringem Bodensatz wie stets bei diesem Stamm. Eine Virulenzeinstellung der frisch von Serum gewonnenen 24stündigen Serumbouillonkultur bei intraperitonealer Infektion hatte das in Tabelle II dargelegte Ergebnis. Wir finden dort die Virulenz des Ausgangsstammes im Juli 1920 der des Ungermannstammes gegenübergestellt.

Tabelle II.

\begin{tabular}{|c|c|c|c|c|}
\hline \multirow{2}{*}{ Stamm } & \multicolumn{4}{|c|}{ Infektion mit $0,5 \mathrm{ccm}$ intraperit. der Verdunnungen } \\
\hline & $1: 10000$ & $1: 100000$ & $1: 1$ Mill. & 1: 10 Mill. \\
\hline $\begin{array}{l}\text { Ausgangsstamm } \\
\text { Juli } 1920 \text { vor der } \\
\text { Konservierung }\end{array}$ & - & $+2 . \mathrm{Tag}$ & - & $\uparrow 3$. Tag \\
\hline Konservierter Stamm & +2. Tag & $\dagger 1$. Tag & + 4. Tag & - \\
\hline
\end{tabular}


Wie aus der vorstehenden Tabelle ersichtlich, hatte sich die Pathogenität des Streptokokkus Aronson seit dem Juli 1920 nicht wesentlich verändert.

Auch dieser Stamm hat sich mithin im Serum mindestens $3 / 4 \mathrm{Jahr}$ virulent erhalten; nach fast 2 jährigem Aufenthalte in einem Ungermannröhrchen war jedoch die Lebensfähigkeit der Keime erloschen.

Bei den frisch vom Menschen gezüchteten hämolytischen Streptokokkenstämmen gelingt es nicht immer, Überimpfbarkeit und Virulenz so lange zu erhalten, wie bei den an lange Fortzüchtung schon gewöhnten Laboratoriumsstämmen. Frische hämolytische Streptokokken halten sich, wie wir in zahlreichen Fällen beobachtet haben, nur ungefähr 6-8 Monate lebensfähig. Nach einem Jahre gingen sie bei Ưbertragung aus dem Serumröhrchen auf Blutagár nicht mehr an. Um sicher zu gehen, ist es daher notwendig, solche Stämme in den obengenannten Abständen von 6-8 Wochen zu überimpfen.

Wir geben im folgenden ein Beispiel dafür, wie schnell frisch vom Menschen gezüchtete hämolytische Streptokokken bei der üblichen Fortzüchtung ihre pathogenen Eigenschaften verändern können, und zeigen gleichzeitig, daß sich die ursprüngliche Pathogenität bei der Konservierung in Serum konstant erhalten läßt.

Es handelt sich um den Streptokokkus 19, der auch in anderer Hinsicht von Interesse ist. Er war aus Urin gezüchtet worden und ging uns als völlig avirulenter, grünwachsender Stamm zu. Ein bald. nach seiner Gewinnung angelegtes Serumröhrchen wurde 20 Tage darauf abgeimpft. Es wuchsen nur spärliche grüne Kolonien. Der von diesen Keimen weitergezüchtete Stamm schlägt nach 4-5 maliger Überimpfung in den hämolytischen Zustand um, und der von hämolytischen Einzelkolonien fortgezüchtete Stamm spaltet bei fraktionierter Aussaat keine grünen Kolonien mehr ab. Die tödliche Dosis dieses hämolytischen Stammes war $0,3 \mathrm{ccm} 1 / 1000$ Kultur bei intraperitonealer Infektion; noch $0,2 \mathrm{~cm} 1 / 10000$ 24 stündiger Serumbouillonkultur subcutan am Mäusebauch eingespritzt, erzeugten nach 24 Stunden Phlegmonen. Mit größeren Dosen $-0,2 \mathrm{~cm}{ }^{1} / 400 ; 0,2 \mathrm{ccm}{ }^{1} / 200-$ gelang es, Phlegmonen zu erzeugen, die noch nach 6-8 Tagen bestanden. Am 7.IV. wurde vom hämolytischen Streptokokkus 19 ein Serumröhrchen nach Ungermann angelegt, davon wurde am 17. IV. auf Blutagar und Serumbouillon abgeimpft und in der Folgezeit der Stamm zu zahlreichen Tierversuchen benutzt. Am 19. IV. wurden 5 Mäuse mit $0,2 \mathrm{ccm} 1 / 250$ Kultur des Streptokokkus 19 subcutan am Bauche infiziert; 3 von diesen nach 18 Stunden getöteten Mäusen hatten schon ausgedehnte Phlegmonen, aus denen dichteste Rasen hämolytischer Streptokokken wuchsen. Zwei Mäuse, die nach 6 Tagen getötet wurden, boten das gleiche Bild. Der Stamm wurde in dem üblichen Turnus vom festen 
zum flüssigen Nährboden fortgezüchtet und etwa 14 Tage später nochmals in derselben Dosis - 0,2 $1 / 250-4$ Mäusen subcutan am Bauche eingespritzt; diese Tiere wurden nach 24 Stunden getötet; nur 2 von ihnen zeigten eine deutliche Phlegmone. Das Ergebnis der Abimpfung des Subcutangewebes auf Blutagar ist in der Tabelle III wiedergegeben.

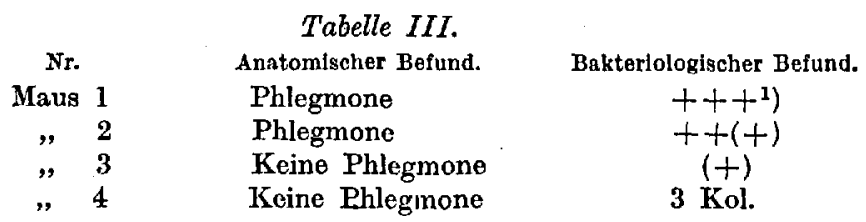

Der Stamm ging jetzt recht unregelmäßig an, war also durch die Fortzüchtung deutlich abgeschwächt. Wir entnahmen deshalb noch einmal dem am 7. IV. beimpften Serum Material und legten Kulturen auf Blutagar und in Serumbouillon an, die gut angingen. Auf Blutagar wuchsen reichlich hämolytische Kolonien. Mit der 24stündigen Serumbouillonkultur wurden Mäuse infiziert, und zwar erhielten 2 Tiere je $0,2 \mathrm{ccm} 1 / 250$ und 2 weitere je $0,21 / 50024$ stündiger Serumbouillonkultur subcutan am Bauche. Nach 24 Stunden getötet und seziert boten die 4 Mäuse stark entwickelte Phlegmonen der Bauchdecken dar; bei der Abimpfung auf Blutagar wuchsen dichteste Rasen hämolytischer Kolonien.

Während die Tierpathogenität der in üblicher Weise 16 Tage hindurch fortgezüchteten KuItur des hämolytischen Streptokokkus 19 deutlich abgeschwächt war, hatte sie sich bei den in Serum nach Ungermann aufbewahrten Keimen voll erhalten lassen.

Von der Dauer der Konservierungsmöglichkeit in Ungermannröhrchen geben uns Untersuchungen an dem hämolytischen Streptokokkus Re ein Bild, das wir nach unseren Erfahrungen als charakteristisch für das Verhalten frischer hämolytischer Menschenstämme bei dem Verweilen in Serum ansehen können.

Streptokokkus Re., Ende Januar 1921 aus einer Phlegmone gezüchtet, wächst in Serumbouillon diffus trübe mit geringem Bodensatz, auf Blutagar bildet er zarte Kolonien mit starken hämolytischen Höfen. Bei einer intraperitonealen Virulenzeinstellung tötei en $0,3 \mathrm{ccm}$ einer $1: 100$ verdünnten Serumbouillonkultur Mäuse nach 24 Stunden, wobei eine untere Grenze nicht erreicht wurde. Bei subcutaner Einspritzung am Bauche erzeugen 0,2 com einer $1: 100$ verdünnten Serumbouillonkultur eine Phlegmone, aus der ein dichter Rasen hämolytischer Streptokokken wächst. Am 10. II. 1921 wurde der Strep-

1) +++ bedeutet dichtester Rasen konfluierter Kolonien, ++ dichter Rasen gut trennbarer Kolonien, (+) wenige Kolonien (bis 50) hämolytischer Streptokokken. 
tokokkus Re in ein Serumröhrchen abgeimpft (I), von dem am 5. X: 1921 in neues Serum übertragen wurde (II). Von diesem. zweiten Röhrchen wurde am 29. XII. 1921 ein drittes beimpft. ·Am 28. IV. 1922 wurden aus den 3 Röhrchen Kulturen in Serumbouillon und auf Blutagar angelegt; über ihr Wachstum gibt Tabelle IV Auskunft.

\begin{tabular}{lcll} 
Dauer des Aufent- & Tabelle IV. & \multicolumn{1}{c}{ Wachstum } \\
Stamm & $\begin{array}{c}\text { haltes im Serum } \\
\text { Re I }\end{array}$ & etwa 14 Monate & $\begin{array}{l}\text { unbewachsen } \\
\text { in Serumbouillon }\end{array}$ \\
Re II & etwa 7 Monate & hämolyt. Kolon. & trübe m. Bodensatz \\
Re III & 4 Monate & hämolyt. Kolon. & trübe m. Bodensatz.
\end{tabular}

Es wurde bei den beiden 7 und 4 Monate konservierten Stämmen das Verhalten der Tierpathogenität untersucht; und zwar haben wir uns zur Prüfung der subcutanen Infektion bedient, da für die frischen Menschenstämme das Angehen im Subcutangewebe der Maus unter Bildung einer subcutanen Phlegmone besonders charakteristisch ist und ein gutes Bild von dem Verhalten der tierpathogenen Eigenschaften gibt.

Von 24stündigen Serumbouillonkulturen der beiden Stämme II und III werden mit steriler Bouillon Verdünnungen $1: 10,1: 100$, $1: 1000,1: 10000$ hergestellt und von einer jeden $0,2 \mathrm{ccm}$ je einer Maus subcutan am Bauche eingespritzt. Nach etwa 48 Stunden werden alle Mäuse durch Chloroform getötet und sofort seziert; es wird vom Subcutangewebe auf Blutagar abgeimpft. Das Ergebnis ist aus der folgenden Tabelle $V$ zu ersehen.

\begin{tabular}{|c|c|c|c|c|}
\hline \multirow{2}{*}{$\begin{array}{l}\text { Infektionsdosis : } \\
0,2 \text { cem } \\
\text { der verdünnungen }\end{array}$} & \multicolumn{2}{|l|}{$\operatorname{Re} I I$} & \multicolumn{2}{|c|}{ Re $I I I$} \\
\hline & Anatom. Befund & auf Blutagar & Anatom. Befund & auf Blintagar \\
\hline $1: 10$ & Phlegmone & $+t+$ & Phlegmone & + \\
\hline $1: 100$ & Phlegmone & $+t+$ & Phlegmone & +++ \\
\hline $1: 1000$ & Phlegmone & $t+t$ & Phlegmone & $+t+$ \\
\hline $1: 10000$ & Keine Phlegmone & 0 & Spur Phlegmone & $+t+$ \\
\hline
\end{tabular}

Die Untersuchungen am Streptokokkus Re zeigen zunächst, daß der frisch von einer menschlichen Erkrankung gezüchtete hämolytische Stamm nach mehr als einjährigem Aufenthalt in Serum seine Überimpfbarkeit eingebüßt hatte. Dagegen gingen Keime, die über ein Halbjahr und länger als ein Vierteljahr in Serumröhrchen gehalten waren, bei UUbertragung auf unsere üblichen Nährböden noch reichlich an und waren tierpathogen. Gegenüber dem letzten und jüngsten Stamme III ist die Tierpathogenität des älteren (II) etwas abgeschwächt; die zur Erzeugung einer Phlegmone ausreichende Dosis ist mindestens um das Zehnfache höher. Eine völlige Vergleichsmöglichkeit mit dem Verhalten des im Januar 1921 gewonnenen Ursprungsstammes haben 
wir nicht, da wir seinerzeit den Stamm nur bis zu einer Kulturverdünnung 1:100 eingestellt hatten; nach unseren Erfahrungen an frischen Streptokokken ist aber nicht anzunehmen, daß der Stamm wesentlich höher pathogen gewesen ist, als er sich heute nach der Konservierung uns darstellt.

Die beiden letzten angeführten Beispiele ließen deutlich den Wert des Semumverfahrens für die Konservierung frischer Streptokokken, aber auch die Grenze, die dieser Methode für die Erhaltung der Lebensfähigkeit der Keime durch die Zeit gesteckt ist, erkennen. Welch große Erleichterung des experimentellen Arbeitens mit Streptokokken Ungermann geschaffen hat, liegt mithin auf der Hand.

Wir müssen jedoch darauf hinweisen, daß die bisher mitgeteilten Tatsachen nur für hämolytische Streptokokken Geltung haben.

Untersuchungen, die wir an grünwachsenden Streptokokken - sowohl an solchen, die direkt vom Menschen gezüchtet waren, als auch an experimentell nach der von Schnitzer und Munter (l. c.) angegebenen Methode vergrünten hämolytischen Streptokokken - angestellt haben, zeigten, daß manche derartige Stämme sich nur sehr kurze Zeit nach Ungermann konservieren lassen. Es sei hier nur kurz über eine Versuchsreihe (Tabelle VI) berichtet, in der ungefähr gleichaltrige Serumkulturen von hämolytischen und grünwachsenden Streptokokken, die sämtlich frisch aus menschlichen Erkrankungen gezüchtet waren, auf ihre Lebensfähigkeit geprüft wurden. Die Stämme wurden gleich. zeitig vom Serum auf Blutagar und Serumbouillon verimpft.

Tabelle VI.

\begin{tabular}{|c|c|c|c|c|}
\hline \multirow[b]{2}{*}{ Aufenthalt der stầmme im Serum } & \multicolumn{2}{|c|}{ Hämolyt. Streptokokken } & \multicolumn{2}{|c|}{ Grilnwachs. Streptokokken } \\
\hline & $\$ \operatorname{stamm}$ & Wachstum & Stamm & Wachstum \\
\hline 95 Tage & Str. 10 & üppig & Str. 7 & 0 \\
\hline 54 Tage & Str. 29 & üppig & Str. 28 & 0 \\
\hline 12 Tage & Str. 44 & üpp'g & Str. 48 & spärlich \\
\hline
\end{tabular}

Während also, entsprechend unseren früheren Angaben, hämolytische Streptokokken noch nach 95 Tagen und ebenso nach 50 und weniger Tagen von Serum auf Blutagar oder Sor mmbouillon verimpft üppig angingen, war die Lebensfähigkeit der gleichalten grünwachsenden Stämme bereits erloschen und selbst in der 12 Tage alten Kultur des Streptokokkus 48 schon deutlich vermindert. Doch müssen wir ausdrücklich feststellen, daß es auch grüne Stämme gibt, bei denen die Wirkung der Ungermannschen Methode eine bessere ist. Wir hiben neuerdings solche Streptokokken 2 Monate hindurch in Ungermannserum ihre Lobensfähigkeit bew hren sehen.

Wir konnten hier natürlich nur charakteristische Beispiele aus unserem sehr reichen Material geben. 
98 F. Pulvermacher: Über die Konservierung von Streptokokken usw .

Die Gesamtheit unserer Erfahrungen läßt sich in folgenden Sätzen zusammenfassen:

1. Hämolytische Streptokokken können in Serumröhrchen nach Ungermann längere Zeit lebensfähig und in ihrer Tierpathogenität sowohl in bezug auf die Dosis letalis wie in bezug auf die Erzeugung subcutaner Phlegmonen unverändert erhalten werden.

2. Für Mäuse hochvirulente, durch mehrfache Mäusepassagen gegangene Laboratoriumsstämme bleiben länger als ein Jahr quantitativ vollvirulent.

3. Frisch vom Menschen gezüchtete hämolytische Streptokokken bewahren ungefähr 6-8 Monate voll ihre pathogenen Eigenschaften. Um sicher zu gehen, empfehlen wir Überimpfung auf Blutagar und erneute Beschickung von Ungermannröhren alle 2 Monate.

4. Nichthämolytische, grünwachsende Streptokokken werden nicht regelmäßig 2 Monate hindurch lebend erhalten.

5. Die Ungermannmethode leistet erheblich mehr als die dauernde Fortzüchtung für die Konservierung der Streptokokken und bietet dabei den Vorteil größter Ersparnis an Nährboden und Arbeit. 